\title{
Conjunto habitacional Residencial Macapaba, na cidade Macapá-AP: direito à cidade?
}

\section{Macapaba Residential housing development, in the city Macapá-} AP: right to the city?

Naiara Videira dos Santos - Doutoranda no Programa de Pós-graduação em Sociologia e Antropologia na Universidade Federal do Pará (UFPA). E-mail: nay-videira@hotmail.com

Edila Arnaud Ferreira Moura - Doutora em Desenvolvimento Socioambiental, pelo Núcleo de Altos Estudos Amazônicos (NAEA) da Universidade Federal do Pará (UFPA). Professora Titular de Sociologia da Universidade Federal do Pará (UFPA). E-mail: eafmoura@gmail.com

\section{Resumo}

Este trabalho objetiva analisar o direito à cidade a partir da transferência de moradores para o conjunto habitacional de moradia popular, o Residencial Macapaba, localizado na cidade de Macapá-AP. O empreendimento faz parte do Programa Minha Casa Minha Vida II, voltado à população da Faixa I, pessoas de baixa renda e em situação de vulnerabilidade socioeconômica. Nesse estudo, aborda-se o direito à cidade na inter-relação com o direito à educação, à saúde, ao transporte, ao lazer e à segurança, considerados fundamentais para promover o acesso de pessoas à cidade e aos seus recursos. A pesquisa demonstrou limitações impostas aos novos moradores para a efetivação do direito à cidade com impacto no alcance da qualidade de vida urbana. Como instrumentos para a análise fez-se uso da pesquisa bibliográfica, observação direta e a aplicação de questionários semiestruturados com 40 moradores da Fase I do empreendimento.

\section{Palavras-chave}

Direito à cidade. Residencial Macapaba. Conjunto de moradia popular. Política habitacional.

\begin{abstract}
This paper porpose analise the right to city from transference of residents to a popular housing residential, Macapaba Residential, located in Macapa city, Amapa. The project is on Minha Casa, Minha Vida II program, oriented to the people of Range 1, people of lowincome and vulnerability socioeconomic situations. In this study, we approach the city entitlement in the interrelationship with the education right, health, means of transport, leisure and security, has been considered as fundamental to promote the access of people at town and theirs resources. The research demonstrates limitations imposition to new residents for effective approach to the city whit the impact at urban quality life. As an analytical tool, been used of bibliographic research, direct observation and application of semi-structured questionnaires in forty residents of stage one of the project.
\end{abstract}

\section{Keywords}

Right to the city. Residencial Macapaba. Popular housing set. Housing policy. 


\section{INTRODUÇÃO}

Discutir os processos de produção e reprodução do espaço urbano nas sociedades capitalistas contemporâneas, requer analisar um conjunto de fenômenos e processos que tem assumido novas formas e novos conteúdos com vistas a garantir a ampliação e a manutenção do capital. Nesse aspecto, o controle sobre o espaço urbano deixa de ser apenas um meio de reprodução ou de respostas para as sucessivas crises do capitalismo, mas também e, principalmente, um mecanismo para sua expansão ao se constituir em uma mercadoria, e mais ainda na atualidade, em um ativo financeiro.

No âmbito da política pública de habitação, o direito à moradia não deve estar desvinculado do direito à cidade. Esta condição se faz necessária, pois o alcance da qualidade de vida, necessariamente, traz como condição ter um habitat digno, mas este só pode se realizar plenamente em sua interface com a garantia de direitos sociais, que possibilite, principalmente, aos grupos sociais mais vulneráveis acessarem os espaços urbanos e com isso minimizar as desigualdades existentes nas sociedades capitalistas no acesso à cidade.

Este trabalho objetiva analisar o direito à cidade a partir da transferência de moradores para o conjunto habitacional de moradia popular, o Residencial Macapaba, localizado na cidade de Macapá-AP. O empreendimento foi construído em duas etapas, a primeira fase no ano de 2014 e segunda fase concluída em 2017, com a edificação total de 4.366 unidades habitacionais, direcionadas às famílias incluídas na faixa I do programa (renda até $\mathrm{R} \$ 1.600,00)^{1}$.

Trata-se do maior empreendimento habitacional de moradia popular no estado do Amapá, com previsão de residência para 31 mil habitantes, constituindo uma população de moradores maior do que a população existente nos 13 municípios dos 16 que fazem parte deste estado, na região Norte do país.

Neste sentido, faz-se importante que, além da oferta da moradia digna, seja garantido a essas populações o acesso a um conjunto de direitos sociais, em sua maioria, materializados nos serviços e equipamentos urbanos, possibilitando-os, dessa forma, exercerem o direito à cidade e o alcance de uma melhor qualidade de vida. Afinal, de acordo com Sposati (2001, p. 37), "é pela relação com os serviços públicos que o morador acessa as condições de qualidade de vida urbana”.

Para esta análise de abordagem qualitativa, fez-se uso da pesquisa bibliográfica e métodos da pesquisa de campo, como a observação direta e a aplicação de questionários semiestruturados com 40 moradores contemplados na

1 De acordo com as novas diretrizes do Ministério das Cidades, atualmente a FAIXA I corresponde à renda de até $\mathrm{R} \$ 1.800,00$. 
FASE I do programa e, portanto, com maior tempo de vivência no habitacional, no período de julho a dezembro de 2017. Para a definição da amostra adotouse o processo de amostragem aleatória simples. A realização do sorteio ocorreu englobando as 08 quadras do conjunto da Fase I, selecionado 05 apartamentos de cada quadra respectiva, totalizando 40 unidades familiares.

\section{A PRODUÇÃO E A REPRODUÇÃO DO ESPAÇO URBANO NA CIDADE CONTEMPORÂNEA: CIDADE MERCADORIA $X$ DIREITO À CIDADE}

Com o desenvolvimento das sociedades capitalistas, a produção do espaço adquire novos contornos, novas formas e novos conteúdos, deixando de ser apenas uma condição necessária para a reprodução da vida humana, para também e, principalmente, tornar-se um meio de reprodução do capital. Pois, a partir da separação entre os meios de produção e a força de trabalho, característica fundamental desse novo sistema, a transformação do espaço passa a ser mediada, cada vez mais pela mais-valia e pela busca de acumulação do capital (LEFEBVRE, 2001).

O capitalismo constitui o espaço como meio de reprodução do capital ao transformá-lo em mercadoria. E, sob a égide do sistema capitalista, a produção do espaço urbano revela a sua contradição básica, pois "sua reprodução é social, enquanto que sua apropriação é privada" (CARLOS, 2017, p. 35). Dessa maneira, amplia-se o processo de desigualdade entre os indivíduos devido à forma diferenciada com que alguns grupos se apropriam dos espaços citadinos no curso da reprodução da vida humana.

Cardoso (2007) salienta que o espaço urbano na base do sistema capitalista se caracteriza como um campo de disputa, por um lado, entre os interesses pela apropriação dos benefícios e vantagens na produção da renda e no alcance do lucro e, do outro, a luta por melhores condições de vida materiais e simbólicas.

$\mathrm{Na}$ atual fase de expansão do capitalismo, em que os ativos financeiros se voltam à produção do espaço e, com base no modelo de urbanização neoliberal, vem ocorrendo significativas mudanças nas estruturas econômicas, políticas e territoriais nas cidades do planeta, em geral, assentadas em um padrão de consumismo globalizado que se impõe sobre a organização e o modo de produção do espaço urbano.

A cidade neoliberal tem se caracterizado como um espaço extremamente perverso para os excluídos e os marginalizados, limitando as suas possibilidades de se fixar em algum lugar (BENACH, 2017). Nessa condição, cresce o número 
de assentamentos informais em que os moradores assumem a condição de transitórios permanentes, pois são espaços que podem deixar de existir na cidade a qualquer tempo (ROLNIK, 2015).

Dentro desse contexto, emerge cada vez mais a importância do direito à cidade, termo elaborado por Henri Lefebvre, na década de 1960, para tratar das questões da sociedade urbana durante a segunda metade do século XX. Na atualidade, diversas interpretações têm sido utilizadas na análise do termo, configurando um vasto campo de conceitos e demonstrando sua importância contemporânea como uma potência explicativa e transformadora no estudo do urbano.

Para Lefebvre (2001), o direito à cidade pressupõe o direito à vida urbana, remodelada e com novas formas e conteúdos. Trata-se, dessa maneira, da construção de uma sociedade a partir da produção de um novo espaço, o que implicaria uma ruptura com o poder do Estado e do capital.

Lefebvre (2001) defende a ideia de uma revolução da classe operária objetivando a conquista de direitos sociais como educação, habitação, trabalho digno e a vida, estes concebidos como o direito à cidade. E, dessa maneira, o valor da vida se sobrepõe à mercadoria, à troca e ao mercado.

Harvey (2014) também compreende o direito à cidade como a maneira de produzir o espaço urbano visando a superação do modelo capitalista e de suas estruturas. Mas, indo além de Lefebvre (2001), enfatiza a importância do direito coletivo da população de participar das decisões sobre o desenvolvimento da urbanização.

Carlos (2016) em suas análises concebe o direito à cidade como a condição do uso pleno do espaço e o seu direito à apropriação de forma a romper com o processo de segregação socioespacial e, com isso, eliminar a produção do espaço urbano na lógica do sistema capitalista. Dessa forma, "a superação da segregação socioespacial encontra seu caminho na construção do direito à cidade, como projeto social" (CARLOS, 2016, p. 109).

Para Verdi e Nogueira (2017), o direito à cidade também se configura numa relação oposta ao caráter capitalista de produção da cidade, a qual se baseia, principalmente, na lógica de consumo. Os movimentos em oposição ao sistema capitalista deverão se constituir, portanto, numa produção coletiva, mas que somente conseguirão se efetivar quando de fato superado o modo de produção do espaço sob a égide do capital.

Em outra perspectiva, Maricato (1995) argumenta que o direito à cidade parte do pressuposto da garantia de acesso à urbanização bem como à habitação legal, pois embora seja crescente a ocupação irregular da terra urbana e ainda assim tolerada, e isso na medida em que esses espaços não constituam interesse 
para o capital imobiliário, a possibilidade de obtenção da posse legal dessas áreas é mínima, quando não rara. A cidade constitui-se como uma luta de classes, em resumo, a luta por condições de vida urbana (ERMíNIA, 2016).

Rodrigues (2007) também procura demonstrar que o direito à cidade se constitui como a luta para acessar a cidade. Nesse sentido, as condições precárias de moradia dos grupos menos favorecidos os levariam a se organizarem coletivamente, fazendo com que as formas de exploração e de espoliação no meio urbano tornem-se mais visíveis. O autor concebe que "o direito à cidade é a luta pelo direito à vida" (RODRIGUES, 2007, p. 87).

No atual contexto da luta pelo direito à cidade têm surgido diversos movimentos sociais a nível local, nacional e global. Em suas manifestações de resistências e de reivindicações, de uma forma geral, o direito à cidade tem sido associado à conquista de direitos como acesso à habitação adequada, ao saneamento ambiental, à educação, à saúde, ao transporte público de qualidade, ao lazer, à alimentação, à informação, ao trabalho remunerado adequadamente e à vida em cidades mais sustentáveis e mais democráticas. Trata-se de reivindicar, portanto, o direito à vida urbana.

Nessa perspectiva, o direito à cidade relaciona-se ao alcance de qualidade de vida urbana que perpassa pelo atendimento de direitos sociais, devendo ser assegurados através de políticas públicas mais igualitárias e universalistas. Para tanto, no processo de implementação das referidas políticas é importante que sejam consideradas as diferenças entre os agentes sociais que compõem o cenário urbano, para que sob o lema do combate às desigualdades socioespaciais na cidade, não sejam mascaradas ainda mais as contradições existentes no espaço urbano capitalista.

\section{O CONJUNTO RESIDENCIAL MACAPABA: DIREITO À CIDADE?}

\subsection{O RESIDENCIAL MACAPABA: ASPECTOS GERAIS}

O Conjunto Habitacional Residencial Macapaba integra o Programa Minha Casa Minha Vida II (PMCMV II) do Governo Federal que teve a contrapartida do Governo do Estado do Amapá, por meio do Programa de Obras e Ações para Mudar o Amapá (PROAMAPÁ). Para sua construção foram investidos mais de $\mathrm{R} \$ 200$ milhões através dos recursos do Fundo de Arrendamento Residencial (FAR).

O terreno do conjunto possui uma dimensão de $1.039 .353,00 \mathrm{~m}^{2}$ adquirido pelo Governo do Estado do Amapá e, posteriormente, repassado 
ao Fundo de Arrendamento Residencial (FAR). A sua construção ficou sob a responsabilidade da Empresa Direcional Empreendimentos, selecionada através de chamamento público.

A execução do conjunto Residencial Macapaba dividiu-se em duas fases, denominadas Macapaba-fase I (2012-2014) e Macapaba-fase II (2014-2017), com a edificação total de 4.366 unidades habitacionais, divididas em 4.032 apartamentos e 334 casas. A população-alvo do empreendimento constitui-se, originalmente, de moradores das áreas alagadas e dos bairros periféricos da cidade em situação de vulnerabilidade social e risco pessoal, social e ambiental.

No entanto, o programa tinha como meta inicial atender simultaneamente três faixas de renda: a de 0 até 3 salários mínimos, cujo padrão das edificações das moradias corresponderia à construção das casas térreas de $45 \mathrm{~m}^{2}$ em lotes no tamanho de $138 \mathrm{~m}^{2}$ e blocos de edifícios com 4 pavimentos cada, com 4 apartamentos por andar, correspondendo a 16 apartamentos em lotes de $600 \mathrm{~m}^{2}$; a população de 3 até 6 salários mínimos, com lotes de $675 \mathrm{~m}^{2}$ e também com edifícios de 4 pavimentos, com 4 apartamentos por andar, totalizando 16 apartamentos; e, para o segmento populacional com renda de 6 até 10 salários mínimos, seriam planejados edifícios com 4 a 10 pavimentos, com um total de 12 a 36 apartamentos em lote irregular, sendo 4 por andar (TOSTES; LUZ, 2014). Porém, como já ressaltado anteriormente, na execução do programa Residencial Macapaba, as unidades habitacionais restringiram-se à faixa I com renda de até $\mathrm{R} \$ 1.600,00$.

Ressalta-se que, mesmo após a finalização total das obras em 2017, foram identificadas 300 unidades habitacionais sem uso, as quais estariam destinadas à população encaminhada pelo Estado através de demanda dirigida. De maneira geral, a população total estimada para o conjunto Residencial Macapaba corresponde a 31 mil habitantes.

O empreendimento está localizado às margens dos quilômetros finais da Rodovia BR-210, no bairro Brasil Novo, Zona Norte de Macapá, circunscrito por apenas três bairros, o bairro Açaí, os bairros Infraero I e II e ainda pelo Loteamento Morada das Palmeiras De acordo com os dados do IBGE (2010), antes da construção do Residencial Macapaba viviam no bairro Brasil Novo aproximadamente 13.273 habitantes, constituindo 3,3\% da população do município de Macapá, distribuídos em 3.731 domicílios em uma área de 8,9 $\mathrm{km}^{2}$.

No que se refere à localização do conjunto, situa-se em uma área na franja da malha urbana do município em descontinuidade com o tecido urbano, aproximadamente $10,1 \mathrm{~km}$ de distância da região central, contando com pouco ou quase nenhum equipamento ou serviço público ao entorno. Esses fatores, por sua vez, têm gerado impactos significativos para a realização do direito à cidade 
na sua inter-relação com os direitos sociais, considerados fundamentais para o alcance da qualidade de vida urbana.

\subsection{O ACESSO AOS SERVIÇOS E AOS EQUIPAMENTOS PÚBLICOS NA PERSPECTIVA DO DIREITO À CIDADE NO CONJUNTO RESIDENCIAL MACAPABA}

O conjunto habitacional Residencial Macapaba configura-se como política pública de oferta de moradia popular. Nesta análise, o direito à cidade é compreendido na sua inter-relação com um conjunto de direitos sociais de responsabilidade do Estado, tais como educação, saúde, transporte, lazer e segurança, considerados fundamentais para a garantia do acesso à cidade com todos os seus recursos e equipamentos urbanos.

\subsubsection{O direito à educação}

O direito à educação é fundamental na formação da cidadania dos indivíduos, possibilitando-os a se reconhecerem como sujeitos de direitos e de deveres e, dessa forma, podendo vir a fomentar a participação das populações nos processos de luta por cidades mais igualitárias, mais dignas e mais sustentáveis frente aos processos de espoliação das cidades mercadorias nas sociedades capitalistas neoliberais.

Mas para isso, garantir o acesso aos estabelecimentos de ensino tornase um pressuposto fundamental, em que fatores como a oferta e a localização acabam condicionando em maior ou menor proporção o desenvolvimento do processo educativo. Portanto, vindo a impactar diretamente na formação de cidadãos que possa de fato transformar e renovar o espaço urbano na perspectiva do direito à cidade.

Nesta análise, identificaram-se os bairros das escolas frequentadas em 2017 pelos filhos dos moradores do conjunto, analisando a proximidade e a distância desses equipamentos em relação à nova moradia. Dessa maneira, constatou-se que, em $75 \%$ dos casos, a localização dá-se em bairros distantes do conjunto habitacional e que somente $10 \%$ conseguiram vagas em escolas nos bairros ao entorno. Tais dados evidenciam que, para a maioria dos filhos desses moradores, o acesso à educação, a partir da mudança para o conjunto Residencial Macapaba, passou a exigir maior deslocamento, como demonstrado no Gráfico 1. 
Gráfico 1 - Localização das escolas frequentadas pelos novos moradores em relação ao Conjunto Residencial Macapaba

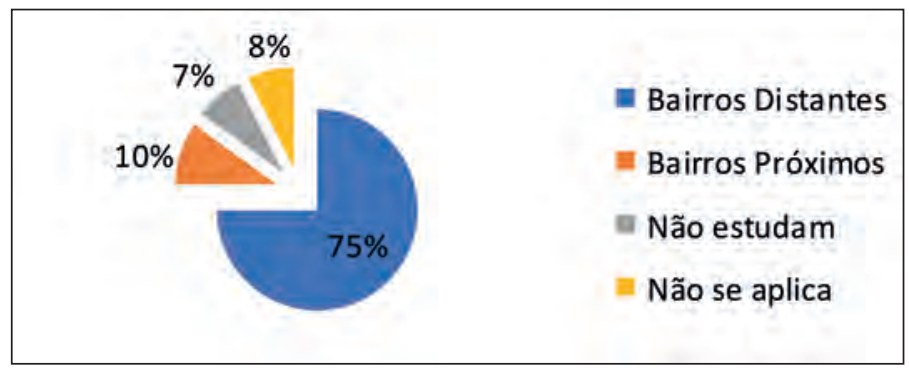

Fonte: Elaborado pelas autoras, 2018.

Os entrevistados foram questionados sobre as principais dificuldades encontradas para o acesso à educação após a mudança de moradia para o conjunto habitacional. As respostas obtidas revelaram que para $46 \%$ a principal dificuldade era a localização das unidades de ensino, as quais ficam distantes do conjunto habitacional, como já ressaltado anteriormente; para 39\%, as dificuldades se relacionam ao aumento dos gastos com transporte coletivo, reflexo da distância desses equipamentos e que tem impactado na renda das famílias; e, para 15\%, deve-se a maior exposição às situações de violência a que passaram a ser submetidas as crianças e os jovens no trajeto casa-escola-casa, devido a necessidade do maior deslocamento, também reflexo da localização das unidades escolares. De forma sintética, no Gráfico 2, são apresentadas as referidas informações.

Gráfico 2 - Principais dificuldades apontadas pelos moradores para garantir o acesso à educação de seus filhos, a partir da mudança para o conjunto Residencial Macapaba

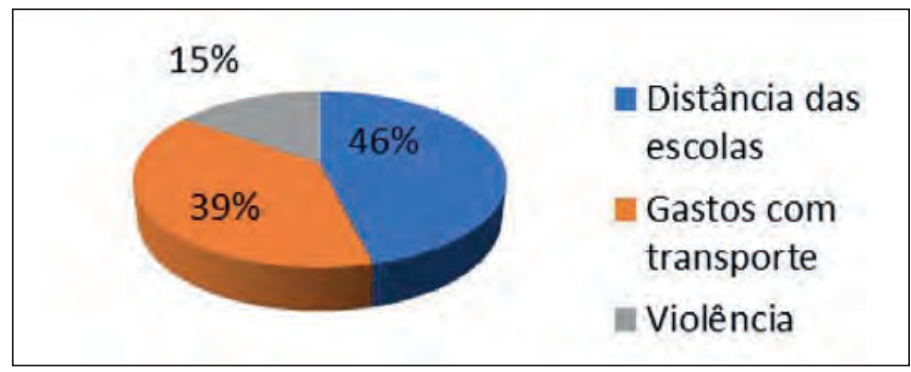

Fonte: Elaborado pelas autoras, 2018. 
As respostas revelam que, com a mudança para o conjunto habitacional Macapaba, os novos moradores vêm enfrentando dificuldades para efetivar o direito à educação de seus filhos. A inexistência de unidades escolares no conjunto ou nas intermediações, capaz de atender a demanda, tem sido a principal responsável pelo aumento do problema e que consequentemente acaba ocasionando outros fatores negativos, como o aumento nos gastos com o transporte e a exposição maior às situações de violência urbana.

Sabe-sequeo direitoà educação, além deestargarantidoconstitucionalmente, trata-se de um direito universal, pois a educação de fato pode transformar as vidas, ao formar cidadãos mais conscientes e mais comprometidos com um projeto de mundo mais igualitário. No campo das lutas pelo direito à cidade contra a terra e a moradia como um ativo financeiro, a educação dos povos se constitui num importante mecanismo para levar a uma verdadeira mudança na sociedade capitalista neoliberal.

No caso dos moradores do conjunto habitacional Macapaba é preciso que seja garantido o acesso efetivo à educação e não somente a oferta da moradia, como se apresenta na realidade.

\subsection{2 $\mathrm{O}$ direito à saúde}

O direito à saúde se relaciona no campo das lutas pelo direito à cidade, na medida em que se faz importante a garantia de espaços urbanos saudáveis e menos poluídos para a população. Trata-se de buscar a redução das desigualdades socioespaciais e com isso possibilitar a todos, principalmente, aos grupos sociais menos favorecidos, o usufruto dos ganhos positivos da urbanização. Nessa perspectiva, a inter-relação do direito à cidade com o direito à saúde configurase como base para a promoção da equidade (FIGUEIREDO et al., 2017) e consequentemente uma contraposição ao ideal da cidade mercadoria capitalista.

Neste trabalho, visou-se, entre outros objetivos, identificar a localização das redes de atendimentos de saúde acessada pelos moradores após a mudança para o conjunto habitacional. Entre os entrevistados 70\% informaram que os locais de atendimento frequentados são os considerados pelos moradores como os mais próximos do conjunto. Dentro desse percentual a distribuição ocorre da seguinte maneira: 46\% utilizam a Unidade Básica de Saúde (UBS) do Brasil Novo, seguido com 29\% pela Unidade de Pronto Atendimento do Novo Horizonte, 11\% a UBS Rubin Brito Aronovitch, 7\% a UBS Marcelo Cândida e, por fim, 5\% a UBS do Perpétuo Socorro. 
Porém, a proximidade dos equipamentos de saúde em relação ao conjunto habitacional Residencial Macapaba, como pode ser identificado na pesquisa, não se trata necessariamente de uma curta distância, não sendo possível, inclusive, de serem acessados a pé. Em sua maioria, com a exceção da UBS do Brasil Novo, a relativamente mais próxima, as demais unidades localizam-se a km de distância do habitacional, o que pode implicar em dificuldades no acesso a esses serviços básicos. O Gráfico 03 apresenta em km a distância dessas unidades de saúde em relação ao conjunto.

Gráfico 03 - Distância em km das principais unidades de saúde consideradas mais próximas do Residencial Macapaba

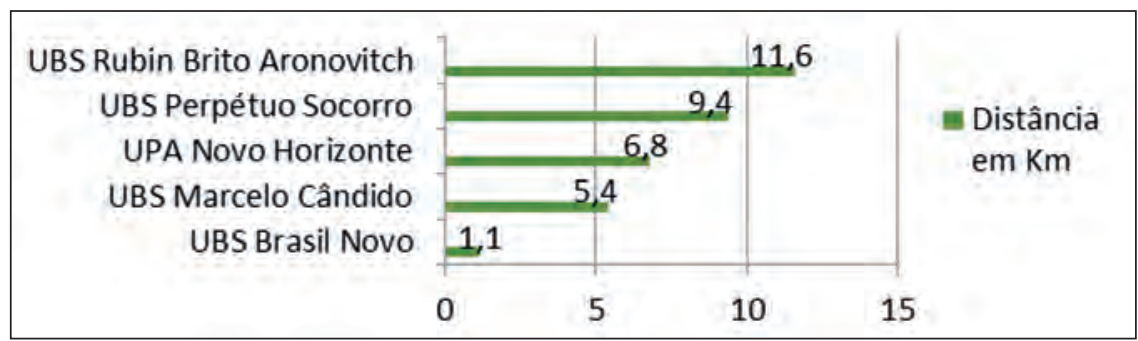

Fonte: adaptado pelas autoras a partir do Google Maps, 2018.

Na análise geral sobre a ampliação ao acesso aos serviços de saúde na nova moradia, identificou-se que para 80\% dos casos têm ocorrido maiores dificuldades na busca e no acesso aos atendimentos; para 2,5\% houve a melhoria desses serviços e, para 17,5\%, não existiram mudanças em relação às residências anteriores.

Entre os moradores que destacaram a ampliação das dificuldades de acesso aos serviços de saúde, o principal fator apontado foi a distância do conjunto em relação às unidades de saúde mais próximas, registrado por $69 \%$ dos entrevistados. Ainda, 3\% destacaram a incapacidade dessas unidades para atender a demanda uma vez que não possuem em seus quadros as principais especialidades de atendimento médico e, com isso, os moradores são obrigados a procurar os serviços em unidades de saúde ainda mais distantes, como é o caso do Pronto-Socorro de Macapá, localizado à distância de 20,5km do conjunto.

Outros 19\% destacaram a inexistência de uma unidade básica de saúde no habitacional, o que já possibilitaria um maior acesso aos serviços, ressaltando que existe um projeto para a construção desse equipamento no conjunto Residencial Macapaba, mas as obras não foram iniciadas. Para 6\%, deve-se ao aumento nos gastos com o transporte público, devido à necessidade de realização de maiores deslocamentos para outros bairros em busca dos serviços. E, finalmente, para 
3\% deve-se à demora na chegada do Serviço de Atendimento Móvel de Urgência (SAMU) no habitacional. O Gráfico 4 apresenta uma síntese das principais dificuldades destacadas pelos moradores no acesso aos serviços de saúde após a mudança para o conjunto.

Gráfico 4 - Principais dificuldades apontadas pelos moradores para acessar as unidades de saúde, após a mudança para o Residencial Macapaba

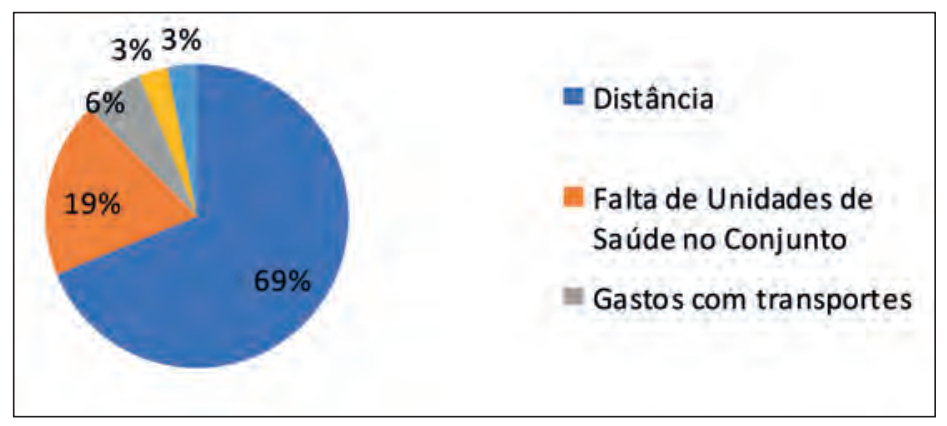

Fonte: Elaborado pelas autoras, 2018.

Diante do exposto, percebe-se que aos novos moradores tem sido imposta uma série de limitações ao seu direito à saúde com reflexos diretamente na sua qualidade de vida. Não se trata apenas da necessidade de um maior deslocamento para acessar as unidades de saúde distantes do conjunto, mas também toda uma série de fatores como maior gasto do tempo do seu dia, o aumento de gastos com o transporte, a insegurança quando necessitam sair de madrugada, podendo levar até mesmo a privação desses serviços.

$\mathrm{Na}$ oferta da moradia digna deve ser considerado o direito à saúde como um pressuposto fundamental, o que implica condições de acesso aos equipamentos e aos serviços de atendimento médico e hospitalar. No caso do conjunto Residencial Macapaba, a realidade demonstra que vem ocorrendo um prejuízo na efetivação desse direito e, dessa maneira, não se alcança o direito à cidade na sua inter-relação com o direito à saúde no que tange a garantia e a promoção do bem-estar dessas populações para o atendimento de necessidades humanas básicas.

Novamente, percebe-se a ideologia das sociedades capitalistas, as quais impõem na cidade-mercadoria a sobreposição dos direitos individuais seletivos sobre os direitos coletivos, como é o caso do direito à saúde, pois o que passa a importar são as relações e os interesses realizados por meio dos mercados (RODRIGUES, 2007). 
A política pública habitacional, no entanto, deve ser formulada com vistas a se contrapor aos processos de dominação e de espoliação do meio urbano capitalista, com vista a possibilitar o direito à cidade como pressuposto para o alcance de qualidade de vida urbana.

\subsubsection{O direito ao transporte}

O direito ao transporte público constitui-se outro componente-chave para a realização do direito à cidade, principalmente, quando se trata do mais usual meio de locomoção das pessoas no espaço citadino.

Dessa maneira, no âmbito do direito à cidade, a política de transporte público deve ser instauradora do acesso, principalmente, dos ambientes públicos, de forma a assegurar aos cidadãos os benefícios de todos os recursos existentes, assim como o ingresso no espaço citadino por todas as camadas sociais. Porém, sabe-se que na lógica da cidade mercadoria capitalista, o acesso aos espaços urbanos vai se constituir, cada vez mais, um campo de lutas pelo direito de ir e vir nessa cidade (RODRIGUES, 2007).

$\mathrm{Na}$ análise sobre o direito ao transporte constituindo-se como um fator para a realização do direito à cidade no conjunto Residencial Macapaba, buscouse traçar um panorama sobre o acesso e a execução dos serviços nesse conjunto habitacional. Visa-se, assim, identificar as melhorias nas condições de mobilidade dos novos moradores e, consequentemente, na sua qualidade de vida após a mudança para o conjunto.

Inicialmente, identificaram-se os principais meios de locomoção utilizados pelos novos moradores. Foram obtidos os seguintes resultados: 45,5\% utilizam exclusivamente o serviço de transporte público coletivo (ônibus), outros 45\% fazem uso parcialmente desse transporte coletivo, pois fazem uso também de serviços de mototáxi, bicicleta, entre outros; e 7,5\% se locomovem unicamente com seus veículos próprios (motos).

Quanto à qualidade do serviço prestado pelo transporte público aos moradores desse conjunto habitacional, destacou-se que para 80\% dos entrevistados há uma deficiência nos serviços, sendo apontado como principal problema o fato das linhas de ônibus que atendem o conjunto não possibilitarem o deslocamento para os bairros mais distantes, necessitando, em sua maioria, o uso de dois ou mais coletivos para chegarem ao destino final. Outros 20\%, ao contrário, ressaltaram a suficiência do serviço, mas em geral, são deslocamentos para as áreas mais próximas ou em direção ao centro. De acordo com Santos (1990, p. 248), de "modo geral, quanto mais longe é a moradia, tanto mais tempo 
é gasto com transporte contabilizando o percurso dentro do veículo e o que é feito a pé para alcançá-lo”.

Tem-se, dessa maneira, a contabilização de um maior tempo dentro ou a espera do coletivo, já que não existe um número suficiente de linhas de ônibus capaz de atender às reais necessidades dos novos moradores, uma vez que, o habitacional localiza-se em uma área fora do perímetro urbano, o que dificulta o acesso às rotas de ônibus que não sejam as exclusivas para a área onde se situa o conjunto.

Outro dado importante, diz respeito aos gastos no mês com o uso do serviço de transporte coletivo na nova moradia em comparação com a residência anterior. Com a mudança para o Residencial Macapaba, para 35\%, os gastos com transporte coletivo representaram um aumento de $\mathrm{R} \$ 200,00$ a $\mathrm{R} \$ 300,00$; também para outros 35\%, o aumento significou de $\mathrm{R} \$ 100,00$ a $\mathrm{R} \$ 200,00$; para $7,5 \%$ o aumento foi menos de $\mathrm{R} \$ 100,00$; para 5\% o aumento apresentou-se mais elevado de $\mathrm{R} \$ 300,00$ a $\mathrm{R} \$ 400,00$ e ainda, para 2,5\% os gastos subiram acima de $\mathrm{R} \$ 500,00$.

Fazendo uma comparação com a moradia anterior, os gastos mensais com transporte coletivo apresentaram-se menor em relação ao empregado, atualmente, pelos moradores do Residencial Macapaba. Conforme os dados obtidos a esse respeito, para 65\%, a média de gastos representava, anteriormente, menos de $\mathrm{R} \$ 100,00$; para $10 \%$ de $\mathrm{R} \$ 100,00$ a $\mathrm{R} \$ 200,00 ; 7,5 \%$ faziam uso do passe social e que continuam usando mesmo após a mudança; e, 17,5\% não utilizavam transporte coletivo, deslocando-se a pé ou de bicicleta, devido à proximidade das residências dos locais de trabalho e das escolas frequentadas pelos filhos. No Gráfico 5, apresenta-se a comparação entre os gastos no mês com transporte coletivo no conjunto Residencial Macapaba e na moradia anterior:

Gráfico 5 - Gastos em percentual com transporte coletivo no mês, no conjunto Residencial Macapaba em comparação com os gastos na moradia anterior

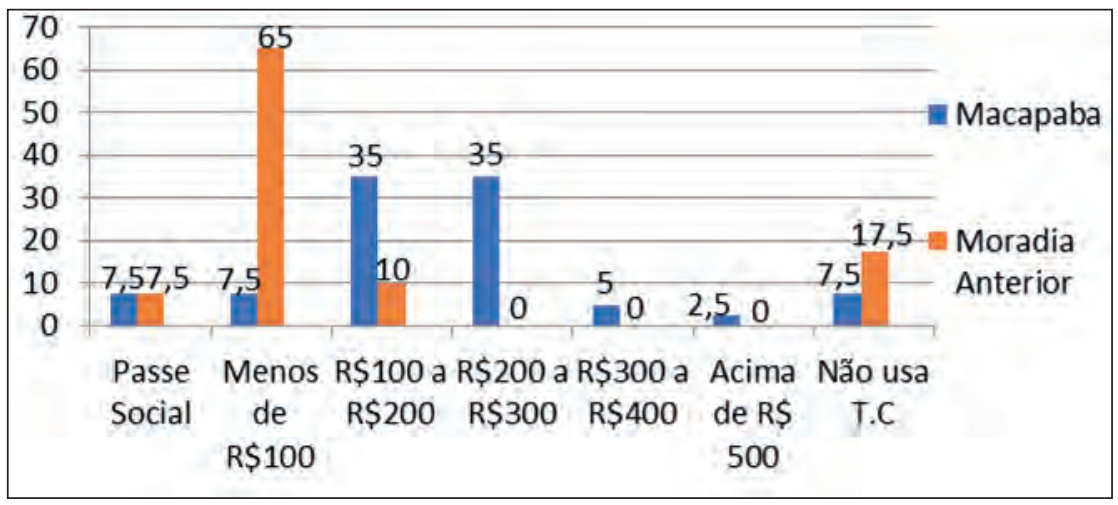

Fonte: Elaborado pelas autoras, 2018. 
Conforme os dados expostos, observa-se um impacto significativo nos gastos com transporte coletivo na renda dessas famílias com a mudança para o Residencial Macapaba - principalmente, tratando-se em sua maioria, de famílias de baixa renda ou que recebem programas de transferência de renda, como o Bolsa Família - pois é evidente a diferença no aumento dos gastos com esse tipo de transporte na atual moradia em relação às antigas residências.

O aumento dos custos com transporte no orçamento familiar é um dos fatores que pode impulsionar as famílias mais afetadas por esse aumento nos gastos familiares a abandonar o programa habitacional. E ainda, dificultar o acesso a outros espaços da cidade, quando as famílias não possuem recursos financeiros para pagar pelo serviço e não contam com outro tipo de transporte. Os dados obtidos na pesquisa evidenciam que a renda familiar desses moradores tem sido fortemente impactada pelo uso do transporte público.

Pelo exposto, observa-se dificuldade para o amplo acesso aos serviços de transporte coletivo pelos novos moradores do Residencial Macapaba. Tais problemas podem gerar limitações no direito de ir e vir desses moradores na cidade, resultando inclusive em impedimentos de acesso aos serviços, aos equipamentos e aos espaços públicos quando o acesso ocorre principalmente pelo uso do transporte público. Nesse cenário, fica comprometida a efetivação do direito à moradia e do direito à cidade e, consequentemente, o alcance de melhor qualidade de vida dessas populações.

A política pública habitacional deve ser instaurada do acesso à cidade para a qual o direto ao transporte torna-se um pressuposto fundamental. Pois, não é suficiente apenas a entrega do imóvel residencial, mas também, se faz necessário ofertar as condições adequadas para que os moradores possam habitar a cidade.

Segundo Santos (1990), a ausência de um serviço de transporte público, eficaz e barato pode levar ao que denomina de exílio na periferia, em que a população pobre, de favelas, de áreas periféricas, sai pouco de seus bairros, principalmente, limitados pelo horário de circulação desse transporte, levando a uma guetização e a uma condição de exílio.

Dessa forma, o direito ao transporte como um componente fundamental da realização do direito à cidade, assume a perspectiva que Rodrigues (2007) considera como a luta para acessar a cidade.

\subsubsection{O direito ao lazer}

$\mathrm{Na}$ análise da garantia do direito à cidade considera-se também como ponto importante as formas de lazer, buscadas pelas pessoas nas cidades, principalmente, aos finais de semana. Nesta abordagem, o direito ao lazer está 
diretamente ligado ao uso dos espaços públicos, para os quais deve ser garantido a existência e a manutenção e, por isso, é também importante compreender os fatores estimulantes ou inibidores de seu uso. Bauman (2001, p. 50) destaca que esses locais devem se constituir como "espaços públicos abertos, convidativos, acolhedores, que todo tipo de cidadão teria vontade de frequentar assiduamente e compartilhar de bom grado".

Dessa maneira, o direito ao lazer realiza o direito à cidade na medida em que, por meio do fortalecimento da ocupação dos espaços públicos, possa ser possível alterar pelo menos parcialmente o modelo de privatização do espaço urbano, hoje, também presente nas ruas, nas praças e em outros aparelhos de uso público sobre a forma de "barreiras" visíveis e invisíveis.

Para esta análise foram investigadas as formas de lazer buscadas pelas famílias do habitacional Residencial Macapaba. Para isso identificou-se, inicialmente, como as famílias fazem uso dos equipamentos comunitários localizados no conjunto. Foi constatado que, em cada quadra há um centro comunitário com uma área com brinquedos para crianças e uma quadra de futebol pequena.

Dessa forma, detectou-se que 25\% utilizam com maior frequência esses espaços, constituindo-se, inclusive, como a principal área de lazer para os filhos; $12,5 \%$ utilizam apenas de forma esporádica, pois sempre que possível preferem dirigir-se a outros lugares. A maioria, no entanto, num total de $62,5 \%$ não utiliza essas áreas, apontando como motivos a insegurança, a depredação e a falta de manutenção que impossibilitam o seu uso.

Em outra perspectiva, identificou-se a existência de espaços públicos de lazer em relação às moradias anteriores e ao uso dessas áreas por esses moradores. O percentual obtido revelou que 52,5\% dos domicílios contavam com espaços dessa natureza nas proximidades de suas residências e que para 47,5\%, a localização dessas áreas situava-se distante das moradias.

No uso que esses moradores faziam dos espaços de lazer próximos das residências antigas, o percentual foi de 67\% de utilização, contra 33\% que consideravam espaços inapropriados para levar as famílias.

Em relação aos moradores que utilizavam com maior frequência as áreas de lazer localizadas no entorno das antigas moradias, os principais motivos destacados foram: 36\% apontaram a proximidade em relação às suas residências, $57 \%$ usavam para os passeios com a família e 7\% destacaram a segurança.

Nos Gráficos 06 e 07, abaixo, são destacados os principais fatores apontados pelos moradores para uso e para o não uso dessas áreas existentes nas proximidades de suas moradias antigas. 
Gráfico 6 - Principais motivos de uso Gráfico 7 - Principais fatores das áreas de lazer nas proximidades da relacionados para o não uso das áreas moradia anterior

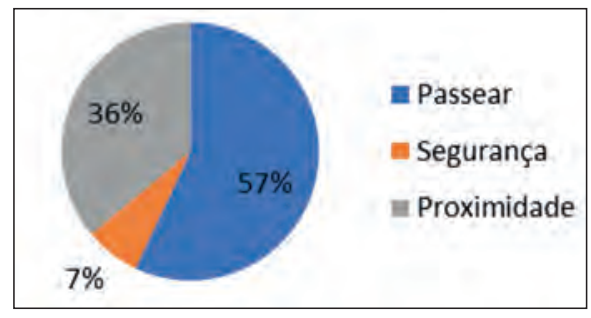

Fonte: Elaborado pelas autoras, 2018 de lazer existentes próximos de suas moradias antigas

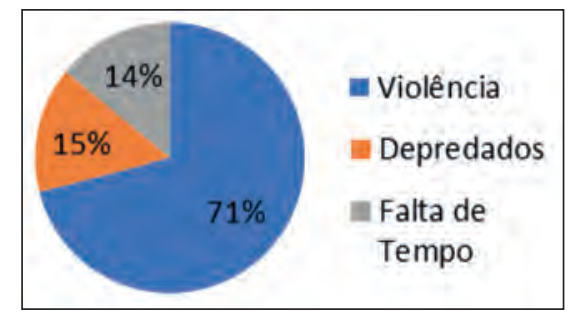

Fonte: Elaborado pelas autoras, 2018

De acordo com o Gráfico 07, pode-se observar, da mesma forma como ocorre no conjunto Residencial Macapaba, que os espaços de lazer públicos, nos poucos existentes, os moradores se deparavam, principalmente, com a insegurança, apontados por $71 \%$, com a depredação, para um percentual de $15 \%$, fatores que limitavam ainda mais o uso pelas famílias. Houve ainda quem alegou não ter feito uso dos espaços, num total de $14 \%$, por falta de tempo.

Ressalta-se que, embora se trate de moradores de diferentes localidades, sejam de áreas de ressacas ou de periferias, de onde a maioria é proveniente, tais locais compartilham de uma mesma realidade do município de Macapá, no qual é escassa a existência de espaços públicos de lazer e, nos poucos existentes, estão presentes os problemas apontados como a violência e a falta ou/pouca manutenção dessas áreas.

Para os novos moradores do Residencial Macapaba fica clara a deficiência no conjunto e no entorno de espaços mais apropriados para os encontros, para as sociabilidades, para a diversão de um modo geral. Pois, nos poucos existentes, o que predomina é a violência e a falta de cuidado, seja por parte do poder público ou dos próprios moradores e, dessa forma, implicando negativamente no uso que fazem desses espaços.

O direito ao lazer como constitutivo do direito à cidade é importante para promover a sociabilidade, os encontros, enfim, uma ocupação da cidade pelas pessoas e para as pessoas e não pelo capital. E dessa maneira, contribuir na luta contra privatização do urbano, com os seus muros visíveis e invisíveis, os quais têm sido crescentes frente à decadência, cada vez mais, dos espaços coletivos. Trata-se, do que Lefebvre (2001) destaca como o valor da vida se impondo acima da mercadoria, da troca e do mercado. 


\subsubsection{O direito à segurança}

Nas sociedades atuais, o problema da segurança tem condicionado diretamente a forma de viver e de se relacionar no espaço urbano, moldando os comportamentos, os hábitos, as relações sociais, vindo a estar no centro das preocupações dos indivíduos na condução de suas vidas nas cidades.

Para Bauman (2009, p. 71), “o ‘milenar’ vínculo entre civilização e barbárie se inverteu. A vida nas cidades está se convertendo em um estado de natureza caracterizado pela regra do terror e pelo medo onipresente que a acompanha".

Dessa forma, o direito à segurança torna-se fundamental para que o indivíduo possa fazer uso do espaço urbano e de seus recursos, garantindo a proteção ao seu bem maior "a vida" e, portanto, a sua liberdade fundamental de ir e vir nessa cidade e com acesso aos demais serviços e equipamentos urbanos. Nessa perspectiva, o direito à segurança assume um dos campos na luta pelo direito à cidade.

Para esta análise, obteve-se informações sobre a percepção dos moradores em relação à segurança no conjunto Residencial Macapaba. A mudança para o habitacional foi propagandeada pela imagem de uma moradia melhor, com a oferta de serviços e de equipamentos públicos, entre eles, a segurança, através da instalação de um Centro Integrado de Bombeiro e Policiamento Militar (CBPM), o qual até os dias atuais, funciona apenas como um posto policial.

Diante da realidade, evidenciou-se que para 52,5\% predomina a insegurança no conjunto Residencial Macapaba, principalmente, devido à frequente incidência de roubos e arrombamentos nas casas/apartamentos e o elevado número de assaltos noturnos que tem contribuído para o aumento dos índices de violência no conjunto habitacional.

Outros 47,5\% consideram segura a nova moradia. Mas, nesse caso, foram identificados dois aspectos importantes: o primeiro, diz respeito à segurança que sentem em comparação às moradias anteriores, já que nestas os índices de violência comparados com a residência atual apresentavam-se mais alarmantes. O segundo, refere-se à sensação de segurança, especificamente, dentro dos apartamentos ou das casas. Observou que muitos desses moradores buscaram alternativas como a colocação de grades nas janelas e nas portas, bem como em alguns blocos foram instalados portões de entrada restringindo o acesso aos moradores e aos seus visitantes. Trata-se, portanto, de uma segurança relativa, em que os de dentro se fecham para os de fora.

Como Bauman (2001, p. 133) destaca que em tempos marcados pelo medo e evitação do outro, "se não puder ser evitado o encontro com estranhos, pode-se pelo menos tentar evitar maior contato". 
O problema da insegurança no conjunto Residencial Macapaba vai refletir em outro aspecto apontado pelos moradores, como o fato de a maioria, 67,5\% evitar saídas sejam sozinhos ou com familiares pelo habitacional, principalmente à noite. Já 32,5\% afirmam ter o costume de sair durante esse horário.

Os motivos apontados entre os moradores que evitam as saídas noturnas pelo conjunto Residencial Macapaba, novamente, se sobressaiu o problema da violência, destacado por $63 \%$ dos casos, que por medo preferem ficar dentro de suas casas ou apartamentos.

Mas, além da insegurança, outros fatores também têm interferido na dinâmica de sociabilidade dentro do habitacional, como o próprio hábito desses indivíduos de não sair de casa, apontado por 30\% e ainda 7\% destacaram a falta de tempo, devido os cuidados com a casa ou estarem no trabalho.

Porém, são os dados apresentados sobre a alta incidência de violência no conjunto que a indicam como um dos grandes problemas enfrentados por esses moradores na nova moradia. Consequentemente, tal fato gera limitações no uso do espaço externo do habitacional e da cidade, pois a insegurança acaba repercutindo nos hábitos e nos comportamentos desses moradores tanto no conjunto quanto na relação direta com o espaço urbano, já que o conjunto habitacional é apenas uma das muitas extensões da cidade.

Vale ressaltar que o problema da violência não é apenas uma particularidade do conjunto Residencial Macapaba, mas que se estende para toda a realidade do município de Macapá. De acordo com a ONG Conselho Cidadão para a Segurança Pública e a Justiça Penal do México, Macapá no ano de 2015, aparecia na posição de $48^{a}$ no ranking internacional das 50 cidades mais violentas do mundo, com uma taxa de 30,25 homicídios por 100 mil habitantes.

O crescimento da violência urbana nas médias e grandes cidades brasileiras reflete um quadro de problemáticas que afeta diretamente a realização do direito à cidade, em que cada vez mais as pessoas deixam de usar os espaços públicos, fechando-se em suas casas, cercadas por mecanismos de vigilância, restritos a quem pode pagar pela mercadoria segurança.

Os conjuntos habitacionais, nesta análise tendo como foco o Residencial Macapaba, têm acompanhado a tendência do aumento da violência e da insegurança tão marcantes nas sociedades capitalistas contemporâneas. Aos seus novos moradores, a vida no conjunto tem sido diretamente impactada por relações em que o direito à segurança não tem se constituído como o direito à cidade. Ressalta-se que o direito à segurança na perspectiva do direito à cidade contribui no combate a mercadorização da cidade e seus processos de segregação 
socioespacial, já que é fundamental para garantir a integridade física das pessoas. E, dessa maneira, pode-se ter um maior uso dos espaços públicos, garantindo-se o direito de ir e vir na cidade sem a ameaça ao seu bem maior que é a vida humana.

Os dados revelam, como já assinalado por Carlos (2016), a importância da construção do direito à cidade como um projeto social para a superação da segregação socioespacial, de maneira a eliminar a produção do espaço urbano sob a égide do sistema capitalista. E nesse sentido, o direito à segurança incorpora o campo para a formação de uma sociedade menos excludente no acesso aos espaços públicos.

\section{CONCLUSÕES}

O direito à moradia deve ser compreendido em sua relação intrínseca com o direito à cidade, de forma a possibilitar o alcance da qualidade de vida urbana, em que sejam garantidos, não somente o acesso ao bem casa, mas também a um conjunto de direitos fundamentais para o desenvolvimento humano e uma vida mais saudável no meio urbano, construindo-se o caminho para cidades mais igualitárias em contraposição às cidades seletivas neoliberais.

Nesse sentido, o direito à cidade se constitui como a busca pela produção do espaço urbano remodelado, com novas formas e configurações socioespaciais em contraposição a financeirização da moradia e da cidade mercadoria capitalista. A luta por direitos sociais, por exemplo, tem-se apresentado como mecanismo para a realização do direito à cidade em diversas partes do mundo.

Nesta análise, propôs-se investigar como se tem efetivado o direito à cidade em relação à educação, à saúde, ao transporte, ao lazer e à segurança pelos novos moradores do conjunto Residencial Macapaba após a mudança para o habitacional.

O estudo demonstrou que as famílias do conjunto estão enfrentando limitações para a efetiva realização do direito à cidade. As unidades de ensino, em sua maioria, estão localizadas em áreas distantes do conjunto habitacional, assim como as unidades básicas de saúde, dificultando o acesso ou até mesmo privando as pessoas de serviços básicos e fundamentais para o seu bem-estar. O transporte público, por sua vez, tem sido um dos responsáveis pelo aumento das despesas dessas famílias e não atende com eficiência as necessidades dos moradores, principalmente, quando se faz necessário deslocamentos para bairros mais afastados da nova moradia.

O lazer, também importante para a qualidade de vida das pessoas, está restrito a espaços dentro do conjunto, onde há risco de violência ou estão malconservados, fatores estes que impedem o seu melhor aproveitamento pelos 
moradores do habitacional. Realidade, esta, que se estende aos poucos espaços de lazer existentes na cidade de Macapá. E por fim, a falta de segurança que também tem comprometido a vivência dentro e fora do Residencial Macapaba, pois a proteção à vida se constitui um pressuposto fundamental para as pessoas se relacionarem e fazerem uso do espaço em que estão inseridas.

Nessa perspectiva, o direito à cidade não se trata apenas de poder viver na cidade, mas também torná-la um espaço produzido por pessoas e para as pessoas. É uma luta contra a espoliação e privação do espaço urbano e, com isso, o direito à construção de espaços mais acessíveis e igualitários. E, portanto, como destaca Ermínia Maricato (ERMíNIA, 2016) inevitavelmente, deverá se constituir como uma luta de classes.

\section{REFERÊNCIAS}

BAUMAN, Z. Modernidade líquida. Rio de Janeiro: Zahar, 2001. 278 p.

BAUMAN, Z. Confiança e medo na cidade. Rio de Janeiro: Zahar, 2009. 94 p.

BENACH, N. Da desigualdade social a justiça espacial. In: CARLOS, A. F. A.; ALVES, G.; PADUA, R. F. (org.). Justiça espacial e o direito à cidade. São Paulo: Contexto, 2017. p. 15-32.

CARDOSO, A. L. Desigualdades urbanas e políticas habitacionais.

Observatório das Metrópoles, Rio de Janeiro, 2007. Seleção Artigos

Científicos. Disponível em: http://www.observatoriodasmetropoles.ufrj.br/ download/adauto_desig_urb_polhab.pdf. Acesso em: 12 mar. 2018.

CARLOS, A. F. A. A prática espacial urbana como segregação e o "direito à cidade" como horizonte utópico. In: VASCONCELOS, P. A.; CÔRREA, R. L.; PINTAUDI, S. M. (org.). Cidade contemporânea: segregação socioespacial. São Paulo: Contexto, 2016. p. 95-110.

CARLOS, A. F. A. A privação do urbano e o "direito à cidade" em Henri Lefebvre. In: CARLOS, A. F. A.; ALVES, G.; PADUA, R. F. (org.). Justiça espacial e o direito à cidade. São Paulo: Contexto, 2017. p. 33-62.

ERMINIA Maricato: “Cidade é luta de classes!”. [São Paulo]: TV Boitempo, 2016. 1 vídeo (4 min) Disponível em: https://www.youtube.com/ watch?v=9R4S6ZaDniU. Acesso em: 12 maio 2018.

FIGUEIREDO, G. L. A. et al. Direito à cidade, direito à saúde: quais interconexões? Ciência saúde coletiva, Rio de Janeiro, v. 22, n.12, p. 3821-3830, out./dez. 2017. Disponível em: http://www.scielo.br/pdf/csc/ v22n12/1413-8123-csc-22-12-3821.pdf. Acesso em: 19 mar. 2018. 
HARVEY, D. Cidades rebeldes: do direito à cidade à revolução urbana. Tradução de Jeferson Camargo. São Paulo: Martins Fontes, 2014. 294 p. IBGE. Censo 2010. IBGE, Rio de Janeiro, 2010. Disponível em: https:// censo2010.ibge.gov.br/. Acesso em: 18 mar. 2018.

LEFEBVRE, H. O direito à cidade. Tradução: Rubens Eduardo Farias. 5. ed. São Paulo: Centauro, 2001. 143 p.

MARICATO, E. Metrópole na periferia do capitalismo: ilegalidade, desigualdades e violência. São Paulo: Hucitec, 1995. 71 p.

RODRIGUES, A. M. Desigualdades socioespaciais: a luta pelo direito à cidade. Revista Cidades, Presidente Prudente, v. 4, n. 6, p. 73-88, ago./dez. 2007. Disponível em: http:/ / revista.fct.unesp.br/ index.php/revistacidades/article/ viewFile/571/602. Acesso em: 16 mar. 2018.

ROLNIK, R. Guerra dos lugares: a colonização da terra e da moradia na era das finanças. São Paulo: Boitempo, 2015. 423 p.

SANTOS, M. Metrópole corporativa fragmentada: o caso de São Paulo. São Paulo: Nobel, 1990. 116 p.

SPOSATI, A. Desafios para fazer avançar a política de assistência social no Brasil. Revista Serviço Social e Sociedade, São Paulo, v. 22, n. 68, p. 54-82, out./dez. 2001.

TOSTES, J. A.; LUZ, R. S. Planejamento urbano na cidade de Macapá: análise do projeto habitacional Macapaba. In: ENCONTRO DA ASSOCIAÇÃO NACIONAL DE PESQUISA E PÓS-GRADUAÇÃO EM ARQUITETURA E URBANISMO ARQUITETURA, CIDADE E PROJETO: UMA CONSTRUÇÃO COLETIVA, 3., 2014, São Paulo. Anais [...]. São Paulo: Mackenzie, 2014. Disponível em: http:/ /www.ufpe.br/ppgdh/images/ documentos/Idmora_cidades5.pdf. Acesso em: 22 mar. 2018.

VERDI, E. F; NOGUEIRA, D. S. O direito à cidade (nas ruas e na universidade) e o devir da sociedade urbana. In: CARLOS, A. F. A.; ALVES, G.; PADUA, R. F. (org.). Justiça espacial e o direito à cidade. São Paulo: Contexto, 2017. p. 95-113. 
